\title{
RESPONSE AND CLINICAL OUTCOME OF CRITICALLY ILL CHILDREN WITH GUILLAIN BARRE SYNDROME ADMITTED TO PICU OF CHILDREN'S HOSPITAL LAHORE
}

\author{
ANILA JAMIL, NIGHAT SULTANA, MUHAMMAD SARWAR, FAREEHA KAUSAR, \\ GHAZALA SHAFFQAT, UMER WAQAR AZEEM \\ The Children's Hospital and The Institute of Child Health, Lahore, Pakistan
}

\begin{abstract}
Objective: To analyze patients with Guillain Barre Syndrome (GBS) requiring intensive care unit (ICU) admission, their course, response to treatment and outcome.

Methods: A retrospective study conducted at ICU of The Children's Hospital Lahore in 194 children with diagnosis of GBS from June 2018 to May 2020. Demographic profile, clinical features, treatment, duration of mechanical ventilation, length of ICU stay and outcome was noted.

Results: Mean age of children was $5.95 \pm 3.1$ years with male predominance $136(70 \%)$. Major proportion were in range of $1-5$ years $93(47.9 \%)$. Mean duration of ICU stay was $21.3 \pm 34.4$ days. Out of 194 patients $125(64 \%)$ received IVIGs while $112(57.7 \%)$ required mechanical ventilation because of rapidly progressive weakness within 24 hours of admission and those who remained on mechanical ventilation for longer period showed AMSAN (Acute motor sensory axonal neuropathy) type of GBS ( $\mathrm{p}$ value $<0.001$ ). Tracheostomy was performed in $22.7 \%$ of patients who were difficult to wean off from ventilator. Among nerve conduction studies AIDP (Acute inflammatory demyelinating polyneuropathy) was predominant $48 \%$ associated with $\mathrm{p}$ value $<0.001$ in those who showed complete recovery, followed by AMSAN 24\%, AMAN (Acute motor axonal neuropathy) $13.4 \%$ and miscellaneous $13.9 \%$. Regarding outcome complete recovery was seen in $28 \%$, minimal residual disability in $70 \%$ and $1.5 \%$ remained ventilator dependent.

Conclusion: Patients of severe GBS often require prolong respiratory support and ICU care. The indicators of poor outcome are rapidly progressive course, severe weakness and axonal neuropathy leading to longer duration on mechanical ventilation.
\end{abstract}

KEYWORDS: Guillain Barre Syndrome, Outcome, intensive care unit (ICU)

How to cite this article: Jamil A, Sultana N, Sarwar M, Kausar F, Shaffqat G, Azeem UW. Response and clinical outcome of critically ill children with Guillain Barre Syndrome admitted to PICU of Children's Hospital Lahore.

Pak Postgrad Med J 2020;31(1): 37-41

This is an Open Access article distributed under the terms of the Creative Commons Attribution License (http://creativecommons.org/licenses/by/3.0), which permits unrestricted use, distribution, and reproduction in any medium, provided the original work is properly cited.

DOI: HTTPS//DOI.ORG/10.51642/ppmj. v31i01.364

Correspondence to: Anila Jamil, FCPS

Senior Registrar, Pediatric Medicine, The Children's Hospital and The Institute of Child Health, Lahore, Pakistan.

Email: d_earthcrust@yahoo.com

\section{INTRODUCTION}

Guillain - Barre syndrome (GBS) is one of the main cause of acute flaccid paralysis (AFP). It is an ascending form of symmetrical paralysis starting from lower limbs, then involving upper limbs with areflexia or diminished reflexes. There may or may not be the involvement of autonomic nervous system or sensory system. CSF findings suggestive of GBS are elevated CSF proteins but without an elevation in white blood cells. Respiratory insufficiency because of respiratory muscle weakness is a very serious complication of GBS. The GBS patients, who are severely affected need careful observation in intensive care setting and ventilatory support can prove helpful in securing life of sick patients. ${ }^{1}$

The symptoms usually evolve over a period of 14 days and clinical nadir is reached within 28 days. The worldwide incidence figures of Guillain Barre Syndrome vary from 1.1-1.8/100,000/year , but statistics are not sufficient regarding its incidence in Pakistan. ${ }^{2}$ Respiratory paralysis due to respiratory muscle insufficiency can lead to death if not managed timely. ${ }^{3}$

The course of GBS in children usually advances 
quickly that can be hazardous for life. If the diagnosis is made on time with subsequent guidance for proper supportive treatment, the outcome will be better definitely. Patients with swiftly advancing course, cranial nerves involvement or respiratory insufficiency should be monitored in ICU setting for supportive care and early administration of IVIGs. ${ }^{4}$

Children with rapidly progressive weakness leading to respiratory paralysis in ICU settings show axonal variant of neuropathy. Around $50 \%$ of the patients usually not respond to definitive therapy despite mortality being low. Decrease muscle power in the initial phase of disease as well as quickly advancing course are the predictors of bad outcome.

While treating patients with GBS along with recognizing bad prognostic indicators will help in wise usage of the minimal funds. ${ }^{5}$ However supportive therapy including mental wellbeing, nutritional rehabilitation, pain relief, and physiotherapy are also important aspects of management. ${ }^{6}$

The purpose of the study was to analyze critically ill patients with GBS, their progression, need for respiratory support, response to management, and their outcome. As there is scarcity of studies on severe GBS patients requiring ICU admission so this study can determine the prognostic outcome in critically ill GBS patients.

\section{METHODS}

This was a retrospective observational study, carried out in Pediatric ICU of The Children's Hospital \&The Institute of Child Health (ICH), from June 2018 to May 2020 after the approval from Institutional Review Board. We used a Proforma for data collection. Non-probability convenience sampling method was used. As the exact prevalence of GBS in the developing countries is not known, data of 2 years 194 patients of GBS presented to ICU was taken. Children of both gender with age range of 1 year to 16 years who were diagnosed as GBS on the clinical basis were included. While patients with anoxic brain insult, those who left against medical advice (LAMA) and those in which the final diagnosis was AFP other than GBS were excluded from the study. In all included patients, information about demographic profile, clinical presentation \& subtypes of GBS were determined. The need for respiratory support with or without mechanical ventilation, duration of respiratory support and ICU stay, tracheostomy need requiring ventilation for more than 14 days, NCS findings, administration of IVIGs in a dose of $2 \mathrm{~g} / \mathrm{kg}$ body weight over 3-5 days in patients with rapidly progressive muscle weakness within 24 hours of admission and subsequent response in the form of motor power improvement were evaluated. Motor power assessment was made on daily basis and outcome mentioned as complete recovery; those who will be weaned from ventilator $\&$ being able to walk, Minimal residual disability; those who will be weaned from ventilator but still needs some assistance and Ventilator dependent who were not weaned off from the ventilator. Data was analyzed by SPSS version 25. Descriptive statistics were used to describe the demographic details like age, gender, duration of ICU stay and duration of ventilation as mean and standard deviation (SD). Qualitative variables like need for respiratory support / mechanical ventilation, tracheostomy, IVIGs given and outcome presented by calculating frequency and percentages. A p-value of less than 0.05 was considered significant.

\section{RESULTS}

A total of 194 patients with GBS fulfilling the inclusion criteria were included. The results of our study showed male predominance $136(70.1 \%)$ over female 58 $(29.9 \%)$ with mean age of $5.95 \pm 3.16$ years. Major proportion of patients were in range of 1-5 years constituting 93(47.9\%) of total patients (Table I).

Table- I Demographics and clinical characteristics

\begin{tabular}{lc}
\hline \multicolumn{1}{c}{ Characteristics } & Number (\%) \\
\hline Age & \\
1-5 Years & $93(47.9 \%)$ \\
5-10 Years & $77(39.7 \%)$ \\
>10 Years & $24(12.4 \%)$ \\
Sex & \\
$\quad$ Male & $136(70.1 \%)$ \\
Female & $58(29.9 \%)$ \\
Type of Respiratory Support & \\
None & $69(35.9 \%)$ \\
Nasal Cannula/FM & $13(6.7 \%)$ \\
Mechanical Ventilation & $112(57.7 \%)$ \\
Tracheostomy & $44(22.7 \%)$ \\
IVIGs & \\
Given & $125(64.4 \%)$ \\
\hline
\end{tabular}

Table II: Duration of Respiratory Support vs NCS

\begin{tabular}{ccccccc}
\hline Duration of & \multicolumn{7}{c}{ NCS } \\
\cline { 2 - 6 } Respiratory Support & AIDP & AMSAN & AMAN & Miscellaneous & Total & p-value \\
\hline 1-14 days & $71(63 \%)$ & $5(4.4 \%)$ & $14(12.5 \%)$ & $22(19.6 \%)$ & $112(57.7 \%)$ & $<0.001$ \\
15-28 days & $21(44 \%)$ & $16(34 \%)$ & $8(17 \%)$ & $2(4.2 \%)$ & $47(24.2 \%)$ & $<0.001$ \\
29-56 days & $2(7.1 \%)$ & $19(67.8 \%)$ & $4(14.2 \%)$ & $3(10.7 \%)$ & $28(14.4 \%)$ & $<0.001$ \\
$>57$ days & $0(\%)$ & $7(1 \%)$ & $0(0 \%)$ & $0(0 \%)$ & $7(3.6 \%)$ & $<0.001$ \\
Total & $94(48.4 \%)$ & $47(24.2 \%)$ & $26(13.4 \%)$ & $27(13.9 \%)$ & 194 & \\
\hline
\end{tabular}


Mean duration of ICU stay was $21.37 \pm 34.46$ days. Out of 194 patients $125(64 \%)$ received IVIGs while $112(57.7 \%)$ required mechanical ventilation because of rapidly progressive muscle weakness within 24 hours of admission and those with longer duration on mechanical ventilation showed AMSAN variety of NCS associated with significant $p$ value of $<0.001$ (Table II).
Tracheostomy was performed in $22.7 \%$ of patients who were difficult to wean off from ventilator. Among nerve conduction studies AIDP was commonest $48.5 \%$ and it was associated with complete recovery showing significant $\mathrm{p}$ value $<0.001$, followed by AMSAN $24.2 \%$, AMAN $13.4 \%$ and miscellaneous $13.9 \%$ (Table III).

Table III: Outcome vs NCS

\begin{tabular}{ccccccc}
\hline \multirow{2}{*}{ Outcome } & \multicolumn{6}{c}{ NCS } \\
\cline { 2 - 7 } & AIDP & AMSAN & AMAN & Miscellaneous & Total & p-value \\
\hline Complete Recovery & $18(33.3 \%)$ & $13(24 \%)$ & $16(29.6 \%)$ & $7(12.9 \%)$ & $54(27.8 \%)$ & $<0.001$ \\
Minimal Residual Disability & $76(55.4 \%)$ & $31(22.6 \%)$ & $10(7.2 \%)$ & $20(14.5 \%)$ & $137(70.6 \%)$ & $<0.001$ \\
Ventilator Dependent & $0(\%)$ & $3(1 \%)$ & $0(\%)$ & $0(\%)$ & $3(1.5 \%)$ & $<0.001$ \\
Total & $94(48.4 \%)$ & $47(24.2 \%)$ & $26(13.4 \%)$ & $27(13.9 \%)$ & 194 & \\
\hline
\end{tabular}

Regarding outcome $27.8 \%$ underwent complete recovery, $70.6 \%$ with minimal residual disability and $1.5 \%$ remained ventilator dependent and there was no death (fig 1).

Fig. 1: Outcome

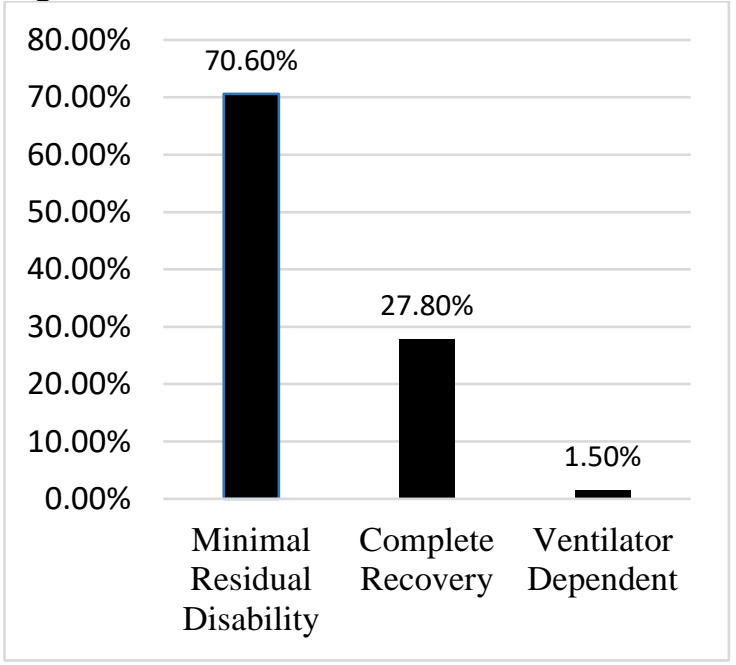

\section{DISCUSSION}

GBS in children occasionally follows a rapidly advancing course often leading to respiratory paralysis that can be hazardous for life. Although clinical course of GBS in every patient is variable and difficult to predict but the role of supportive therapy could be beneficial. In this study 194 patients admitted to PICU of The Children's Hospital Lahore with severe GBS were enrolled. The mean age of the patients was 5.95 \pm 3.1 years that is compatible with research done by Asmat et al. ${ }^{2}$ A mean age of 6.7 years was given by a study from Pakistan. ${ }^{7}$ Major proportion of the patients were in range of (1-5 years) $93(47.9 \%)$ of the total patients and results were comparable to the study from Iran by Ali Akbar Momen et al. which showed 52.2\% of children younger than 5 years. ${ }^{8}$ It could be due to increased risk of infection and likelihood of peripheral myelinated nerves to demyelination in younger age group. Similar results were found in studies from Iraq. ${ }^{9}$ The results of our study also showed a male preponderance and that was comparable with other studies too. However, reason for this preponderance is unclear yet. ${ }^{2}$

Mean duration of ICU stay was $21 \pm 34.4$ days. In a study Nikki Van Leeuwan et al. reported that 26 (31\%) patients stayed in ICU, of which 17 (65\%) were ventilated with median length of stay in ICU for 12 days. Among those with longer duration of stay had axonal neuropathy, rapidly progressive course and severe weakness at presentation leading to financial burden for hospital. ${ }^{10}$

Involvement of respiratory muscles leading to respiratory insufficiency usually found in $20 \%$ of patients with GBS and time period on ventilator may differ among patients. It fluctuates from weeks to months and in some cases could be in years. ${ }^{11}$ In our study out of 194 patients $112(57 \%)$ of patients needed mechanical ventilation. In a research conducted by Christa Walgaar et al. at Netherland reported $27 \%$ of patients at ICU needed mechanical ventilation for a period of 4 weeks, while $71 \%$ of them needed ventilation for $>14$ days. ${ }^{12}$ Tracheostomy should be considered when duration of ventilation expected to exceed for $>14$ days.

In this study $125(64 \%)$ of patients received IVIGs as a part of treatment $31.2 \%$ underwent complete recovery, $66.4 \%$ underwent minimal residual disability and $2.4 \%$ remain ventilator dependent showing p-value $>0.05$ as statistically non-significant. It was generally observed that response to IVIG is favorable in demyelinating and disappointing with axonal neuropathy as said by a study published by Sarmad Hamdani et al. reported that results are still unclear regarding response of IVIG which is contrary to a research conducted by G Kanra et al. who reported considerable efficacy in treating children with GBS. ${ }^{13-}$ 14

NCS findings in our study showed AIDP as the most frequent subtype of GBS (48.5\%), followed by 
AMSAN 24.2\%, AMAN $13.4 \%$ and miscellaneous $13.9 \%$. A latest study at Children's Hospital Lahore also showed AIDP as most common type with frequency of $67 \%$.Similar results were reported by Prem Chand et al. as AIDP (58\%) and results were comparable with study done by Asmat et al. ${ }^{2,7,15}$

Statistics regarding outcome were $28 \%$ underwent complete recovery, $70 \%$ with minimal residual disability and $1.5 \%$ remained ventilator dependent. Generally, GBS has a good prognosis in children with recovery in $85 \%$ of cases. Supportive care and rehabilitation is mandatory for achieving more rapid and global improvement. On the whole prognosis and outcome is good among younger children as reported by Jasem et al. that chances of residual paraparesis were greater in children above 5 years. In a study done by Korinthenberg et al. reported that most of the children $96 \%$ were only had minimal symptoms or even without any symptoms at the end of 41 weeks of diagnosis. ${ }^{(9)}$ In a study conducted at Cairo University by Hafeez M.Bazara et al. showed favorable outcome as patient can take steps without support at discharge were documented in 58\% of cases and severe neurological disability was reported in $13 \%$ by Rees et al. ${ }^{4,16-17}$

\section{STRENGTH AND LIMITATIONS}

It is among the few studies in our setup about the demographics and outcome of the GBS patients admitted to pediatric intensive care unit. Limitation of the study is that it is a retrospective study, long-term prognosis of GBS could not be assessed.

\section{CONCLUSION}

Prognosis of GBS in children is generally good. Patients of severe GBS often require prolong respiratory support and ICU care. However, indicators of poor outcome are rapidly progressive course, severe weakness and axonal neuropathy leading to longer duration on mechanical ventilation. Despite protracted course, results of our study showed that prognosis is good.

\section{ETHICAL APPROVAL}

The study was approved by the Ethical Review Committee of The Children Hospital \& the Institute of Child Health, Lahore, Pakistan. Vide reference No. 2020-154 dated October 14, 2020.

\section{CKNOWLEDGEMENT}

I am really grateful to Professor Dr Attia Bari for suggestions and her kind advice during the preparation of this review.

\section{REFERENCES}

1. Kalita J, Ranjan A, Misra UK. Outcome of guillainbarre syndrome patients with respiratory paralysis. Qjm. 2016;109(5):319-323. 10.1093/qjmed/hcv190

2. Parveen A, Khan SA, Talat S, Hussain SNF. Comparison of the Clinical Outcomes of Guillain Barre Syndrome Based on Electrophysiological Subtypes in Pakistani Children. Cureus. 2020;12(5):8052. 10.7759/cureus.8052

3. Kumar M, Aroor S, Mundkur S, Kumar S. GuillainBarré syndrome: A clinical study of twenty children. J Clin Diagnostic Res. 2015;9(1):SC09-SC12. 10.7860/JCDR/2015/8344.5491

4. Bazaraa HM, Rady HI, Mohamed SA, Rabie WA, ElAnwar NH. Initial Response and Outcome of Critically Ill Children With Guillain Barre' Syndrome. Front Pediatr. 2019;7(September):1-6. 10.3389/fped.2019.00378

5. Bhagat SK, Sidhant S, Bhatta M, Ghimire A, Shah B. Clinical Profile, Functional Outcome and Mortality of Guillain-Barre Syndrome: A Five-Year Tertiary Care Experience from Nepal. Neurol Res Int. 2019;2019(January 2013):1-5. 10.1155/2019/ 3867946

6. Chalela JA. Pearls and pitfalls in the intensive care management of Guillain-Barré syndrome. Semin Neurol. 2001;21(4):399-405. doi:10.1055/s-200119411

7. Chand P, Jan F, Kaleem S, Yousafzai M, Ibrahim S. Description of Guillain-Barre syndrome on the basis of clinical features using Hughes scoring system among children in Karachi, Pakistan. Asia Pacific J Clin Trials Nerv Syst Dis. 2017;2(2):45. 10.4103/ 2542-3932.205193

8. Momen AA, Shakurnia A. The Epidemiology of Guillain-Barré Syndrome in Children under 15 Years Old in Southwest Iran. Biomed Hub. 2017;2(3):1-8. 10.1159/000480693

9. Jasem J, Marof K, Nawar A, Khalaf Y, Aswad S, Hamdani $F$, et al. Guillain-Barré syndrome as a cause of acute flaccid paralysis in Iraqi children: A result of 15 years of nation-wide study. BMC Neurol. 2013;13 10.1186/1471-2377-13-195.

10. Van Leeuwen N, Lingsma HF, Vanrolleghem AM, Sturkenboom MCJM, Van Doorn PA, Steyerberg EW, et al. Hospital admissions, transfers and costs of guillain-Barré syndrome. PLoS One. 2016;11(2):112. 10.1371/journal.pone.0143837

11. Miyamoto M, Imataka G, Ichikawa G, Saito Y, Kashiwagi T, Kaji Y, et al. Successful treatment of a 12-year-old boy with Guillain-Barr syndrome requiring tracheostomy due to respiratory muscle paralysis: A case report. Exp Ther Med. 2019;10914. 10.3892/etm.2019.8311

12. Walgaard C, Lingsma HF, van Doorn PA, van der Jagt M, Steyerberg EW, Jacobs BC. Tracheostomy or Not: Prediction of Prolonged Mechanical Ventilation in Guillain-Barré Syndrome. Neurocrit Care. 2017;26(1):6-13. 10.1007/s12028-016-0311-5 
13. Al Hamdani S, Aljanabi FY, Abdulrasool MI, Salman AH. Child with Guillain-Barré Syndrome Responding to Plasmapheresis: A Case Report. Case Reports Acute Med. 2020;3(1):4-11. 10.1159/ 000505964

14. Kanra G, Ozon A, Vajsar J, Castagna L, Secmeer G, Topaloglu H. Intravenous immunoglobulin treatment in children with Guillain-Barré syndrome. Vol. 1, European Journal of Paediatric Neurology. 1997;1(1). p. 7-12. 10.1016/S1090-3798(97)80004-9

15. Ali S. Spectrum of gullian barre syndrome in children. 2017;12(1):1-6.

16. Rees JH, Thompson RD, Smeeton NC, Hughes RAC. Epidemiological study of Guillain-Barré syndrome in south east England. J Neurol Neurosurg Psychiatry. 1998;64(1):74-77. 10.1136/jnnp.64.1.74
17. Halawa EF, Ahmed D, Nada MAF. Guillain-Barré syndrome as a prominent cause of childhood acute flaccid paralysis in post polio eradication era in Egypt. Vol. 15, European Journal of Paediatric Neurology. 2011(3). p. 241-246. 10.1016/j.ejpn. 2010.11.008 writing
MS: Critical Review
FK: Data Collection
GS: Review \& suggestions
UWA: Data analysis

AUTHORS' CONTRIBUTION:

AJ: Conceived, designed, manuscript writing NS: Supervision and contribution in manuscript 